\title{
Trayectoria artística del pintor Juan Bautista Planeta en Lima. Nuevas noticias y atribución
}

\section{Artistic career of the painter Juan Bautista Planeta in Lima. New news and attribution}

Javier Chuquiray ${ }^{1}$

Universidad Nacional Mayor de San Marcos

\section{Resumen}

Se reseña la trayectoria artística conocida del pintor Juan Bautista Planeta (Lima, 1626-1642), dando a conocer información inédita sobre aspectos biográficos — como la confirmación de su procedencia italiana y su ordenación sacerdotal— e histórico-artísticos — como el activo taller que mantuvo hasta poco antes de su muerte. Asimismo, se propone dos atribuciones a su autoría, mediante documentación: la conocida pintura mural de la capilla del capitán Villegas y un boceto de san Jerónimo. El conocimiento de su obra, vinculada al manierismo italiano, contribuye al panorama de la pintura limeña del siglo XVII, tiempo de transición entre el Manierismo y el Barroco.

1 Javier Chuquiray Garibay, Asistente de Registro y Catalogación, Museo Pedro de Osma. Contacto: javierchg@gmail.com 
Palabras claves: Siglo XVII, Lima, pintura, Juan Bautista Planeta, Manierismo

\section{Abstract:}

It reviews the known artistic trajectory of the painter Juan Bautista Planeta (Lima, 1626-1642), by giving to know unpublished information about biographical aspects — such as the confirmation of his Italian origin and his priestly ordination - and historical-artistic — such as his workshop that was kept until his death. In addition, it is proposed two attributions to his authorship, with documentation: the mural painting of the chapel of captain Villegas and a sketch of St. Jerome. The knowledge of his work, related to Italian Mannerism, contributes to the panorama of painting from Lima of the seventeenth century, time of transition between Mannerism and Baroque.

El trabajo artístico que ha motivado la redacción del presente artículo es la conocida pintura mural conservada en la capilla del capitán Villegas (convento de la Merced, Lima), la cual está vinculada ciertamente con el Manierismo de gusto italiano, y fechada de manera imprecisa en la primera mitad del siglo XVII. ${ }^{2}$ Como se sabe, esta obra pictórica ha concitado

2 La corriente artística denominada Manierismo, que se originó en Italia a principios del siglo XVI, se manifestó en la ciudad de Lima (entre otros géneros) en la pintura y la escultura a finales del mismo siglo y llegó incluso a extenderse tardíamente en la primera mitad del siglo XVII aun cuando a inicios de esa centuria poco a poco se iba a acentuar en las manifestaciones artísticas limeñas novedosas formas de expresión, derivadas 
la atención de los historiadores del arte por la excelente calidad lograda sobre todo en algunos modelos del conjunto, el cual ha sido relacionado con la obra de pintores italianos tales como Mateo Pérez de Alesio (o colaboradores) o Antonio Dovela (Schenone, 1963; pp. 29-37, Mesa y Gisbert, 1972; pp. 121-126, Wuffarden, 1976, Chichizola, 1983; p. 150, Estabridis, 1989; p. 138). En ese sentido, la noticia de mayor relevancia que se da a conocer en este escrito está justamente en relación con la autoría de la comentada obra que se puede atribuir, mediante documentos de época, al pintor Juan Bautista Planeta. ${ }^{3}$

Los investigadores se han ocupado poco de este personaje debido probablemente a que su nombre no ha sido relacionado de modo fehaciente con alguna obra de importancia, en la actualidad. ${ }^{4}$ El investigador Antonio San Cristóbal le ha dedicado un apartado en su libro Arquitectura virreinal de Lima (San Cristóbal, 2005; p. 197), en donde además de actualizar y examinar la información de archivo conocida hasta enton-

de nuevas corrientes de pensamiento y de la exigencia espiritual de la época propias del Barroco, que afectaron finalmente a las artes en dicho periodo. Francisco Stastny ha especificado que la fase del Manierismo que llegó al Perú a finales del siglo XVI, se relaciona con la Contramaniera y Antimaniera, Stastny 2013: 119-149.

3 Esta asignación se hace mediante documentación de archivo, lo cual no descarta la intervención de otros pintores de la época en la decoración pictórica mural que, por lo demás, presenta desigual ejecución en la calidad artística.

4 El investigador Ricardo Estabridis (1982) afirmó que Juan Bautista Planeta era uno de los autores de la pintura mural en el claustro principal del convento de san Francisco, con base en las iniciales que aparecen en uno de los pańos: F.P. (las cuales fue interpretado por el autor como Faciebat Planeta, es decir "lo hizo Planeta" en latín). Pero luego el autor parece moderar su opinión (Estabridis, 1989; p. 139). 
ces sobre el pintor, y dar a conocer documentación inédita sobre su trayectoria artística, destacó principalmente los trabajos de pintura mural que concertó con algunas iglesias limeñas, según consta en los manuscritos. Aunque aún se conoce poco sobre la obra y trayectoria artística de Planeta, la adjudicación de los trabajos de pintura (si no todo, en parte), que se conserva en la capilla sepulcro del capitán Bernardo de Villegas en la iglesia mercedaria, o un boceto de san Jerónimo que se dará a conocer (que puede también atribuírsele), así como otras noticias inéditas, igualmente valiosas, contribuirá no solo al mejor conocimiento de la actividad artística del pintor sino sobre todo a comenzar a perfilar su lenguaje formal, lo cual permitirá finalmente establecer contactos, mediante analogía formal, con trabajos de la época.

\section{Presencia en Lima y su labor en el Monasterio de la Con- cepción}

El lugar de nacimiento de Juan Bautista Planeta-por el momento se desconoce cuándo- fue la ribera de Génova en la villa de dulce agua, ${ }^{5}$ y sus padres fueron Guillermo Planeta y Petronila Guarina. ${ }^{6}$ La primera noticia sobre

5 Emilio Harth-Terré (como después los autores, en general) sospechaba que el apellido de Juan Bautista era de origen italiano, aunque no podía afirmarlo definitivamente, Hart-Terré y Márquez Abanto 1963: 136. La comunidad de Dulce Agua o Dolceacqua se encuentra en la provincia de Imperia, región de Liguria, Italia.

6 Archivo Arzobispal de Lima (en adelante AAL). Pleito de los acreedores a los bienes de Juan Bautista Planeta, legajo 52, expediente 8, ańo 1642, folio 48. La información proviene de un traslado (o copia) del testamento de Planeta, (inserto en el expediente), que fue otorgado ante el escribano Juan de Miranda, el 4 de mayo de 1642. Se consultó en el 
Planeta que consta por ahora en los archivos limeños se remonta al ańo 1626, ${ }^{7}$ cuando el mercader Francisco Rodríguez (de partida para las provincias de México) otorgó poder a Planeta para que este pueda cobrar un total de 480 pesos de a 8 reales por la venta que hizo Rodríguez de un esclavo suyo llamado Cristóbal Angola, de 16 ańos de edad, al bachiller Tomás de la Torre. ${ }^{8}$

$\mathrm{Al}$ año siguiente está registrado un primer concierto de obra —fechado el 13 de enero de 1627- firmado por él y las monjas del monasterio de la Concepción para pintar al óleo lienzos y muros en los sectores que comprendían la capilla mayor y el crucero de su antigua iglesia. Planeta debía entregar acabado dicho trabajo en el plazo de un año y, a cambio, el monasterio de la Concepción debía pagarle un total de 2600 pesos de a 8 reales. ${ }^{9}$ Dos años después —el 8 de julio de 1629- volvió a contratar con el mismo cenobio para ejecutar 14 lienzos de dos varas de alto, pintados al óleo y con

Archivo General de la Nación del Perú (en adelante AGN), pero no se ha podido encontrar protocolos del citado escribano que correspondan con la fecha indicada. Agradezco a la historiadora Silvia Pablo C., por el apoyo brindado en la consulta de los archivos.

7 Aunque es posible que se encuentre en Lima ya en 1624, según declaración de su amigo, Juan de Guedeja Quiroga (en 1642), quien refirió que una esclava llamada Ana Criolla de propiedad de Planeta, le había servido en su casa 18 años atendiéndole sus enfermedades y achaques (folio 78). Recientemente se ha localizado en el AGN, un documento que confirma la estancia de Planeta en Lima en el año 1624: AGN, Francisco Gonzáles Balcázar, protocolo 773, folio 96-96v.

8 AAL, Causa de negros, legajo 6, expediente 20, año de 1632. Agradezco a la directora del AAL, Laura Gutiérrez Arbulú, por brindarme la referencia documental.

9 AGN, escribano Bartolomé de Cívico, protocolo 320, folios 460v-463v. Citado anteriormente en San Cristóbal, 2005; p. 198. 
marcos bruñidos de oro, los cuales decorarían esta vez "todo el cuerpo de la iglesia del dicho convento desde el coro hasta el primer arco de un lado y otro". Por este trabajo cobraría un total de 3000 pesos de a 8 reales, en dos partes; los primeros 1000 pesos para el día 25 de diciembre de ese año, y los 2000 pesos restantes para cuando esté "fecha acabada y sentada la dicha obra de todo punto". ${ }^{10}$

\section{La pintura en la capilla del capitán Villegas}

La construcción de la capilla pertenece a la época en que los frailes mercedarios decidieron ampliar la capacidad de su templo (a partir de principios del siglo XVII), proceso que el investigador Antonio San Cristóbal ha denominado "reconversión" (San Cristóbal, 2009; pp. 101-106), que consistió básicamente en la ampliación del templo por el lado de la cabecera con la construcción de una nueva capilla mayor y dos capillas colaterales, cuya terminación debió de ocurrir probablemente hacia 1616 (San Cristóbal, 2009; p. 213). ${ }^{11}$ Contiguo a estos nuevos espacios se construyó seguidamente una pequeña capilla de oratorio-lavatorio que funcionó como tal hasta 1628, cuando los mercedarios cedieron este ambiente al capitán Bernardo de Villegas quien, como nuevo propietario, ordenó su adaptación

10 AGN, escribano Diego Sánchez Vadillo, protocolo 1769, folios 21472148v. Citado anteriormente en San Cristóbal, 2005; p. 198.

11 Estas modificaciones en la capacidad del templo significaron en última instancia un cambio de estilo arquitectónico, pues se modificó la planta de la iglesia mercedaria, de estilo gótico isabelino, para convertirla en una planta basilical, de estilo barroco parcial (San Cristóbal, 2009; pp. 113-137). 
como capilla funeraria para su propio entierro cuyos muros hizo decorar con pintura. ${ }^{12}$

Aunque Francisco Stastny descartó la posibilidad que el autor de la decoración pictórica haya sido el pintor italiano Mateo Pérez de Alesio, ya que el autor había dado a conocer la fecha aproximada del fallecimiento del pintor acaecida poco antes del 28 de abril de 1616, y no en 1628 (como erróneamente se suponía $\left.{ }^{13}\right)$, algunos investigadores siguieron

12 San Cristóbal, 2009; pp. 113-137. El proyecto de la reconversión arquitectónica en el templo de la Merced comenzó en 1608 pero sufrió la paralización de las obras desde el año 1621 (entre otros factores por un tema económico), las cuales se retomarían a partir del ańo 1628, cuando los frailes de la Merced contrataron con el capitán Bernardo de Villegas la culminación de las obras de su templo. Según el concierto, Villegas se encargaría de costear parte de la construcción de la iglesia, y en retribución los frailes le cedían en donación dos capillas (contiguas al presbiterio), una de las cuales (la que se encontraba junto a la sacristía de la iglesia) fue convertida por el nuevo propietario, como ya se ha mencionado, en su capilla funeraria y decorada con pintura mural la cual se conserva en mal estado, en la actualidad. Posiblemente también construyó un retablo como lo sugiere el concierto de 5 de mayo de 1628 (San Cristóbal, 2009; p. 173, cfr. Barriga, 1944; p. 113).

13 Stastny 2013: 89. Stastny publicó su artículo en 1969, donde reveló que la fecha improbable de 1628, como el año del fallecimiento de Alesio, era un error de imprenta publicado en Lohmann 1940: 2324; y más bien dio a conocer la referencia documental del testamento de Pedro Pablo Morón fechado el 28-04-1616 — que le proporcionó el investigador Emilio Harth-Terré-, donde se menciona a Juan Bello como albacea de los bienes de Mateo Pérez de Alesio. (Se ha actualizado la referencia documental del testamento de Morón AGN, escribano Francisco Hernández, protocolo 825, folios 734-741v.). Por tanto Stastny consideró que era improbable que Alesio fuera el pintor de la capilla, porque esta fue ocupada y transformada en capilla-sepulcro recién en 1628 , por orden de su nuevo propietario el capitán Bernardo de Villegas. 
atribuyendo la obra de pintura conservada en dicha capilla a Alesio (Mesa y Gisbert, 1972; pp. 121-126), — probablemente por la excelente calidad de gusto italiano conseguido en algunos modelos pictóricos del conjunto en cuestión (figs. 1 y 2$)^{14}$ —, sin haber reparado antes en que la capilla que sirve de sustento a la pintura definitivamente no era la capilla mercedaria que funcionó como "oratorio-lavatorio", desde (al menos) el año 1616 hasta 1628, sino es, o era ya otra, puesto que la capilla fue cedida en aquel año al capitán Bernardo de Villegas, que la convirtió seguidamente en una capilla sepulcro mediante construcción de nueva planta (San Cristóbal, 2009; pp. 211, 214).

No se sabe exactamente cuánto duraron las labores de transformación de la capilla mercedaria emprendidas por su nuevo propietario para adecuarla como su sepulcro, ni tampoco cuándo se inició la gran labor pictórica que la decora, pero se puede afirmar que dicho trabajo de pintura fue realizado por Juan Bautista Planeta, quien debió concluirlo en el inicio de la tercera década del siglo XVII, como se explicará en seguida. En una escritura fechada el día 22 de octubre de 1632, Planeta otorgó poder al procurador de causas Juan de Guedeja Quiroga para que en su representación pueda cobrar del capitán Bernardo de Villegas el trabajo "de la pintura y demás/cosas que le hize y puse en su capilla/que tiene en 342 el convento de frayles/de nuestra señora de las mercedes". ${ }^{15}$ En realidad, según se lee en este documento, Bernardo de

14 Agradezco a Luis Martín Bogdanovich por las diligencias que hizo con el fin de ingresar a la capilla Villegas, y al R.P. Fray Pablo Chicata, de la Orden de la Merced, por permitir el acceso y observar la decoración mural que la decora.

15 AGN, escribano Marcos de Santisteban, protocolo 1814, folio 439v. 
Villegas tuvo que ser obligado a pagar a Planeta por el trabajo de pintura que le hizo en su capilla, en virtud de una sentencia dictada por la Real Audiencia. De esta manera, al día siguiente, Juan de Guedeja (en representación de Planeta) pudo cobrar 1080 pesos de Bernardo de Villegas, aunque quedaba aún un saldo de 150 pesos para completar el pago total de 2100 pesos en que había sido sentenciado Villegas a pagarle al pintor. ${ }^{16}$ Es cierto que hasta el momento no se ha hallado el concierto de obra firmado entre Juan Bautista Planeta y el capitán Bernardo de Villegas, que puede informar cuándo (y probablemente bajo qué condiciones) se acordó el comienzo de la obra de pintura en dicha capilla, pero se tiene el testimonio de Juan de Guedeja, quien en una declaración fechada el 2 de noviembre de 1640, dijo "que el año de treinta le encargó Juan/Bautista Planeta le solicytó ser [sic] un pleyto/que seguía con el capitán Bernardo de Villegas/sobre la pintura de un entierro en el convento/de la merced de que cobró el susodicho tres mill/pesos aviendose seguido el dicho pleyto en la/real audiencia y ocupádose en el seguimiento de/más de tres años de que no le pagó cosa/alguna por su trabajo". ${ }^{17}$ Es decir, hacia 1630 Juan Bautista Planeta debió haber acabado hacía poco tiempo la pintura encomendada en la capilla sepulcro. Por tanto, se puede deducir que la ejecución de dicha pintura se produjo después de la cesión de la capilla mercedaria a Bernardo de Villegas (1628), y antes de que Planeta pusiese pleito a su nuevo propietario (1630)

16 Parece ser que la cantidad de 2100 pesos fue el monto que Bernardo de Villegas concertó pagar a Planeta por los trabajos de pintura en su referida capilla, y que posteriormente la Real Audiencia, tras pleito seguido por el pintor contra Villegas, obligó a que se cumpla mediante sentencia. AGN, escribano Marcos de Santisteban, protocolo 1814, folio 470.

17 AAL. Causas civiles, leg. L: 2., folio 6v., 02-11-1640. 
por el incumplimiento del pago correspondiente al trabajo de pintura que hizo en la capilla sepulcro. ${ }^{18}$

\section{Trabajos finales, y su ordenación sacerdotal}

El 29 de agosto de 1637, Juan Bautista Planeta se comprometió con los mayordomos de la cofradía de san Roque para decorar su capilla que tenían fundada en la iglesia de san Sebastián, en Lima. El trabajo que debía realizar Planeta, descrito detalladamente en el contrato, consistió en la decoración pictórica y de dorado tanto en la bóveda (donde representaría dieciséis ángeles y doraría "los bordones de la dicha bóveda") como en los arcos (donde pintaría, entre otros elementos, "algunos ninfos con tarjas"). El encargo también incluía algunos lienzos. Por todo el trabajo referido, el pintor recibiría el pago de 600 pesos de a ocho reales. ${ }^{19}$

18 Podría pensarse que el trabajo de pintura que hizo Planeta fueron lienzos pintados para ornar algún retablo que pudo levantar Bernardo de Villegas en su capilla sepulcro, y no pintura mural; sin embargo, el monto que cobró Planeta por los trabajos de pintura que hizo en dicha capilla (2100 o 3000 pesos, según el procurador Guedeja) corresponde a un trabajo de mayor magnitud, como el que concertó anteriormente con las monjas concepcionistas para decorar al óleo lienzos y muros en el crucero y la capilla mayor de su iglesia, trabajo por el que cobró 2600 pesos de a ocho reales. En un encargo posterior, que se referirá luego, Planeta debió pintar 17 lienzos para un retablo, trabajo por el cual cobró 500 pesos (San Cristóbal, 2005; p. 200), lejos de la suma que cobró por la pintura que hizo en la capilla sepulcro de Villegas. Antonio San Cristóbal apuntó un dato, aunque sin fuente documental, relacionado justamente a un "retablo para la capilla de Villegas", al parecer encomendado a Pedro de Noguera el día 22 de marzo de 1630 (San Cristóbal. 2009; p. 410).

19 Tal como refiere Antonio San Cristóbal, (2005; p. 199, 208-209), los modelos que servirían de inspiración para la decoración de la bóveda de 
El historiador Rubén Vargas Ugarte en su Diccionario de Artífices dio a conocer por primera vez el nombre del pintor Juan Bautista Planeta, a quien le nombró también como clérigo; ${ }^{20}$ y posteriormente, el investigador Emilio HarthTerré publicó algunas noticias más sobre el mismo artífice, al cual le intituló asimismo presbítero. ${ }^{21}$ Pero como ambos investigadores no citaron fuentes, no quedaba claro en qué circunstancias el pintor italiano pasó a ejercer este oficio religioso ni desde cuándo lo ostentaba, si es que pintor y religioso eran la misma persona.

Gracias al hallazgo de un documento fechado el 20 de noviembre de 1637 se puede responder a esas interrogantes. Mediante la escritura en mención, doña Manuela Gudino, monja profesa del monasterio de la Encarnación, nombraba a Juan Bautista Planeta como capellán de la capellanía de su propiedad (instalada en el mencionado monasterio) en virtud a que dońa Gudino, luego de que falleció su padre Gaspar de los Reyes, no tenía a alguien cercano a la familia que pudiera hacerse cargo de la capellanía que fundó su abuelo. Es así que la religiosa decidió nombrar al pintor como capellán "por la buena noticia que/tengo de Juan Bautista Planeta/que es persona de buena vida y/con bienes

esta capilla de san Roque, fueron las capillas de san Nicolás de Tolentino y de santa Lucía, de la iglesia del convento de san Agustín (Lima). Es más, el pintor Domingo Gil para decorar la primera capilla agustina mencionada (1630), debió a su vez tomar como modelo el trabajo que Mateo Pérez de Alesio había hecho en la capilla mayor de la iglesia del convento de santo Domingo (San Cristóbal, 2001; pp. 76, 87).

20 Vargas Ugarte, 1947: 251. Vuelve a reseñar los mismos datos para Planeta en 1968; p. 325.

21 Hart-Terré y Márquez Abanto, 1963; p. 205. 
y de quien e servido/muy buenas correspondencias". ${ }^{22}$ Planeta debió de estar tan honrado y agradecido por tal nombramiento que declaró en el mismo documento "[folio 346v...] [...] Y agradezco a la dicha dońa Manuela el bien/que me hace en el dicho nombramiento/de tal capellán de la dicha ca/pellanía y me obligo que sido/ordenado de tal sacerdote/ansi lo de la guardaré y cumpliré todas/las condiciones y declaraciones que se/consten en tal escritura”.

Una de las obligaciones que debía cumplir Juan Bautista Planeta como capellán, era el de oficiar 4 misas a la semana en favor de las ánimas de los fundadores de la capellanía patrocinada por Manuela Gudino quien, por esa razón, solicitó al "[folio 345v.] [...] ylus/tríssimo señor arzobispo desta/ciudad que al presente es/y adelante fuere den y/concedan las dichas ordenes sa/cerdotales a el dicho Juan Bautista Planeta/y se le dé nominación y canoni/ca ynstrucion y colación de la/ dicha capellanía y en el yn/terin que se ordene de tal/sacerdote porque no se dexen/de decir las misas".

El dictamen de la Iglesia sobre la ordenación sacerdotal de Planeta tardó algunos ańos en emitirse debido a que surgió antes un pleito inesperado entre la religiosa y el bachiller Miguel Flores quien, al parecer, reclamaba derechos de propiedad sobre la capellanía en cuestión. ${ }^{23}$ Sin embargo, el

22 AGN, escribano Cristóbal Aguilar Mendieta, protocolo 66, folios 343$346 \mathrm{v}$.

23 AAL. Causas civiles, leg. L: 2. Autos que sigue Juan de Guedeja contra juan Bautista Planeta por el salario de procurador. Este documento registra el pleito que siguió el procurador Guedeja contra el pintor Planeta fechado en 1640 por el trabajo, no remunerado, consistente en la defensa que hizo el procurador en favor de la monja Manuela Gudino, como heredera de la capellanía, y en contra del bachiller Miguel Flores. Según 
litigio se resolvió en favor de la religiosa quien como propietaria ahora legítima de la capellanía de sus ancestros, volvió a formular su pedido a su señoría deán y cabildo para que le admitan su deseo de ordenar sacerdote a su nombrado capellán, como se lee en una anotación marginal fechada el 6 de diciembre de 1639, en el documento citado. Se sabe que, finalmente, las autoridades religiosas aprobaron el pedido de la monja, como se desprende del testimonio del procurador Guedeja (fechado en 11-10-1640) "y es así que havien/dole defendido [a Juan Bautista Planeta] y cumplido de mi parte/ con todo lo que en mi estuvo obtuvo senten/cia en favor mediante la qual y por este la dicha/capellanía y está hordenado de sacerdote/al título della”. ${ }^{24}$

En cuanto a las actividades como pintor de Juan Bautista Planeta, este fue considerado para un encargo importante destinado a la capilla de Nuestra Señora del Prado, encomendado por el doctor Fernando de Avendaño (canónigo de la Catedral de Lima), ${ }^{25}$ quien contrató el día 2 de marzo de 1638 con el ensamblador Tomás de Aguilar un retablo el cual debía ostentar 15 lienzos que narrarían la vida de la Virgen María, más otros dos que también irían en el altar, uno que retratase al virrey conde de Chinchón y su hijo; y el otro, a

declaró Guedeja, Planeta se había comprometido a costear los servicios del procurador en la defensa de la mencionada religiosa, lo cual el pintor negó en todo momento. La referencia documental se tomó de Rivarola, 2009; p. 243.

24 AAL. Causas civiles, leg. L: 2. Autos que sigue Juan de Guedeja contra juan Bautista Planeta por el salario de procurador, folio 3.

25 AGN, escribano Diego Sánchez Vadillo, protocolo 1795, folio 513-521v. Cfr., San Cristóbal 2005: 200. Según San Cristóbal, anexo a la capilla de Nuestra Señora del Prado, se fundaría luego "el monasterio agustino recoleto derivado del Monasterio de la Encarnación”. 
la señora condesa. En el contrato se menciona que la pintura debía ser de mano de Planeta que cobró finalmente por esa tarea 500 pesos del propio doctor de Avendaño, según declaró el pintor en el mismo documento, en anotación marginal fechada el día 20 de diciembre de 1638.

Como ya se mencionó, el pintor italiano fue ordenado sacerdote entre el año 1639 y 1640 (lo cual le permitió cumplir con sus funciones como nombrado capellán), y en el año 1641 aceptó un nuevo cargo de índole religioso al ser elegido mayordomo en la cofradía del Santísimo Sacramento del hospital de los Niños Huérfanos de Nuestra Señora de Atocha ${ }^{26}$; ambos cargos (capellán y mayordomo) los asumió hasta su muerte acaecida el 7 de mayo de 1642. ${ }^{27}$ En estos últimos años Juan Bautista Planeta, pues, ocupó su tiempo en actividades de culto religioso, entre ellos el de oficiar misas, de manera que no sorprende que se intitulase en adelante presbítero en los documentos que firmó en esa época; sin embargo, él no dejó de trabajar en su casa como pintor, como se demostrará a continuación.

\section{La casa taller de Juan Bautista Planeta}

Aunque no hay más noticias de conciertos de obra firmados por Planeta posterior al año de 1639 , se sabe que siguió ejerciendo el oficio de pintor tal como consta en un extenso expediente de pleito impuesto por los acreedores a sus bienes

26 AAL. Cofradías, LV: 7, años 1642-1643.

27 AAL. Pleito de acreedores a los bienes de Juan Bautista Planeta, legajo 52, expediente 8 , año 1642 , folio 35,50 . 
luego de su muerte. ${ }^{28}$ Dicho expediente contiene documentación importante vinculada a Planeta como son una copia de su testamento, codicilios, memoria de sus bienes, almoneda, y probanzas, las cuales contienen declaraciones valiosas de testigos que le conocieron y le vieron trabajar como pintor en la casa que alquilaba al monasterio de la Encarnación. ${ }^{29}$ Dos de esos testimonios provienen de dos acreedores que trabajaron con Planeta en su casa hasta poco antes de su fallecimiento, se trata del oficial de pintura Luis Lucas Rodríguez y el maestro pintor Martín de Urbina. ${ }^{30}$ Se desconoce la actividad artística del primero pero, según testimonio del presbítero Juan Arias, se sabe que mientras estuvo trabajando en casa de Planeta, por más de dos años, ${ }^{31}$ Rodríguez se había hecho cargo de "[folio 133v.] [...] muchos retratos y lienzos que en la dicha casa se hacían"; es más, según lo declarado por otro testigo, el canciller de la Real Audiencia, Diego de Morales

28 Los primeros, y principales, acreedores en iniciar el pleito para que se cumpla con los pagos de la deuda que tenía Juan Bautista Planeta fueron el monasterio de la Encarnación y la cofradía del Santísimo Sacramento del hospital de los Niños Huérfanos de Nuestra Señora de Atocha. A medida que iba transcurriendo el tiempo se fueron presentando más personas que reclamaban el mismo derecho.

29 AAL. Pleito de acreedores a los bienes de Juan Bautista Planeta, legajo 52, expediente 8, año 1642 .

30 El pintor Urbina fue elegido mayordomo de la cofradía del Santísimo Sacramento del hospital de los Niños Huérfanos de Nuestra Señora de Atocha, el día 11 de mayo de 1642 a pocos días del fallecimiento de Planeta, ver: AAL, Pleito de acreedores a los bienes de Juan Bautista Planeta, legajo 52, expediente 8 , año 1642 , folio 8.

31 Según declaración del propio Luis Lucas Rodríguez afirma que "di servicio/personal y aver trabajado con el dicho difunto/más de dos años", AAL, Pleito de acreedores a los bienes de Juan Bautista Planeta, legajo 52, expediente 8 , año 1642 , folio 22 . También declaró tener 25 años de edad, el 5 de mayo de 1643 (folio 130). 
Aramburú, "[folio 132v] [...] los bienes que oy tiene su Ilustrísima en su casa y los/hizo lo más dello el dicho Luis Lucas Rodríguez y/el dicho Juan Bautista los perfesionaba después de/acabados...".

En cuanto a Martín de Urbina (el segundo acreedor mencionado), ${ }^{32}$ la noticia de mayor interés lo brinda Lucas Rodríguez quien testificó que Urbina “[folio 130] [...] trabajó muchos días en diferentes/tiempos salteados en casa de Juan Bautista Planeta/pintor difunto y por orden y mandato/en diferentes retablos y otras pinturas que le en/cargaba estando enfermo y otras veces con salud/y esto lo sabe este testigo porque lo vido estando traba/jando en la dicha casa como oficial del dicho difunto". Dicho esto, se puede afirmar que Planeta en sus últimos años, a pesar del tiempo que debía dedicar a sus obligaciones como capellán y mayordomo, y de la debilitada salud que padecía, ${ }^{33}$ siguió recibiendo encargos importantes de pin-

32 Solo se ha encontrado algunos datos escuetos sobre el pintor en HarthTerré y Marquez Abanto 1963: 215. Se trata de una venta de dos esclavos suyos a Rafael Sánchez, en 1602; y el trabajo que hace, en compañía del ensamblador Diego Marino, en el altar de la capilla de la Virgen de la Candelaria en el Hospital de san Diego, en 1611. El investigador no citó sus fuentes. En un concierto de 1608, firmado entre el escultor Martín Alonso de Mesa y dońa Juana de Cépeda, donde el escultor se comprometió a hacer un retablo para la capilla de Nuestra Seńora de la Gracia, en la iglesia del convento de san Agustín, se indicaba que la pintura debía ser del pintor italiano Angelino Medoro y los retratos de los patrones, "de mano de Urbina" (folio 304). Ver: AGN; Pedro Gonzáles Contreras, 1608, protocolo 790, folio 302-306v. Cfr., Ramos Sosa 2000: 50; San Cristóbal, 2001; pp. 110, 146.

33 Según el testimonio de una acreedora, dońa Juana Maldonado, demandaba "mandar se me pagar con prelación a toda deuda por ser de ser/ vicio personal estando en casa del susodicho (es decir, Planeta) el año 
tura aunque para ello tuvo que asistirse de al menos dos pintores para cumplir con sus clientes. No es de extrañar, entonces, que luego de que Planeta falleciera, ambos artífices (Luis Lucas Rodríguez y Martín de Urbina) fueran requeridos para completar las pinturas en algunos de los lienzos que el pintor italiano dejó sin acabar, como los retratos de doña María de Herrera y su hija, que fueron culminados por Urbina; o el cuadro de san Joaquín y santa Ana, acabado por Rodríguez (folio 208v.).

Por otro lado, la información contenida en dichos papeles también permite recrear más o menos la actividad artística en la casa taller del maestro poco antes de que falleciera. Así, entre los bienes inventariados en la casa de Planeta, realizado poco tiempo después de su muerte, se contabilizaron 30 cuadros cuya temática variaba entre retratos, religiosos (relacionados a Cristo, la Sagrada Familia, santos, y una advocación mariana), y "dos batallas". Algunos de estos cuadros estaban recién por empezar a pintarse, y otros listos para que el cliente se los pueda llevar, previa cancelación del pago correspondiente. Como no podía ser de otro modo, entre los bienes de Planeta se encontraron materiales tan indispensables en el taller de un pintor como pigmentos almagre, polvos azules, cardenillo, mermellón [sic], sombra negra, ocre-, bastidores, caballetes, y dos piedras de moler. Algunos cuadros no eran suyos, sino prestados, como el lienzo que representaba el arca de Noé (que era de propiedad del relator de la Real Audiencia, el doctor Bartolomé

último en que/murió sirviéndole personalmente un año entero haciendo de comer/y cuidando de la cura y regalo para el su enfermedad que ha padesci/do tan larga que murió" AAL. Pleito de acreedores a los bienes de Juan Bautista Planeta, legajo 52, expediente 8, ańo 1642, folio 71. 
de Salazar), para que Planeta le pueda "sacar una copia" (folio 212v.). A juzgar por la cantidad de retratos hallados entre sus bienes (más de 10, entre empezados y acabados), este tema pictórico debió de ser, junto con el religioso, el de mayor demanda en el taller de Planeta, quien al parecer destacó en ese género pues en alguna oportunidad recibió el encargo del regidor Felipe de Espinosa para pintar "quatro retratos que le hize para ynviar a los reynos despaña” — de cuyo trabajo Espinosa le quedó debiendo al pintor un monto de 200 pesos (folio 50v.). Y en Lima, el canónigo de la catedral doctor Fernando de Avendaño, ${ }^{34}$ también encargó al pintor al menos dos retratos, los cuales no pudo acabar y los dejó solo "en bosquejo". ${ }^{35}$

\section{Un boceto de san Jerónimo penitente en éxtasis}

Se da a conocer un afortunado hallazgo, encontrado en uno de los folios del comentado expediente del pleito de los acreedores a los bienes de Planeta. Se trata de un dibujo o boceto hecho a carboncillo que representa a san Jerónimo penitente (fig. 3), el cual está plasmado en el folio vuelto de una carta de pago fechada el 30 de agosto de 1635, otorgada por el bachiller y presbítero Tomás de Mesa (mayordomo del monasterio de la Encarnación) en virtud del pago que efectuó Juan

34 El doctor Fernando de Avendaño, recordemos, encargó al ensamblador Tomás de Aguilar un retablo que debía ostentar, entre otros lienzos, unos retratos del virrey conde de Chinchón, su hijo y la señora condesa, los cuales debía ser de mano de Planeta, quien cumplió el encargo a satisfacción del doctor Avendaño AGN. escribano Diego Sánchez Vadillo, protocolo 1795, folio $515 \mathrm{v}$.

35 Estos retratos luego "se acabaron por mano de otro maestro", AAL. Pleito de los acreedores a los bienes de Planeta, folio 208v. 
Bautista Planeta por el concepto de alquiler de la casa donde él vivía, de propiedad del dicho cenobio. ${ }^{36}$ Por ser un documento personal de Planeta, y encontrado entre las pertenencias que dejó, puede adjudicársele efectivamente el boceto.

La figura del santo se encuentra en el exterior de una gruta, en posición frontal con el torso (desnudo) y pierna izquierda vueltos ligeramente en tres cuartos en perfil derecho, la rodilla izquierda la apoya sobre un segundo peldaño, y la otra la flexiona un poco y apoya el pie en tierra un paso delante. Viste calzas holgadas hasta las rodillas. Los brazos abiertos, el izquierdo con el codo flexionado sujeta en la mano una cruz larga a media altura; y el derecho, estirado en diagonal hacia abajo, sostiene en la mano una piedra. La cabeza la vuelve hacia atrás, en perfil izquierdo y con la mirada en alto. Detrás del santo en la parte inferior, una cabeza de león, en posición frontal; y delante, un pedestal bajo en donde se disponen una calavera y un reloj de arena sobre un par de libros cerrados, elementos que sugieren el acto de penitencia del santo.

36 Pleito de acreedores a los bienes de Juan Bautista Planeta, legajo 52, expediente 8 , año 1642 , folio $26 \mathrm{v}$. Uno de los principales acreedores a los bienes de Planeta, fue el monasterio de la Encarnación, quien le alquiló una casa "que está junto a la iglesia/de los niños huérfanos" (folio 100v.), a razón de 200 pesos por año, la cual ocupó desde mayo de 1633 hasta el día de su deceso (07-05-1642); es decir, por nueve años. Según el monasterio de la Encarnación, Planeta debía en total 1800 pesos de alquiler, como si no hubiera pagado nada. Ante esta situación su albacea y tenedor de bienes, Pedro Sarmiento, presentó recibos o cartas de pago, hallados entre los bienes de Planeta, donde constaban el cumplimiento del pintor de los pagos de alquiler de la casa donde él vivía. En una de esas cartas de pago presentadas por Pedro Sarmiento, se encuentra el boceto de san Jerónimo penitente. 
La composición de la figura se relaciona con el gusto manierista por el canon alargado, la postura poco natural que adopta el personaje y la desnudez del fuerte torso que confiere sensualidad y contrasta a la vez con la actitud del santo penitente, en cuyo rostro (la zona de mayor ejecución) está definida la psicología del santo arrobado, mediante el uso de líneas y sombras que marcan la enjuta cara de la figura y dan profundidad a los ojos. Si se compara con la versión del mismo tema atribuida a Mateo Pérez de Alesio, el diseño de Planeta resulta con mayor contenido espiritual. ${ }^{37}$ Como boceto, la calidad artística radica en el uso de pocos y simples trazos para sugerir el escorzo del torso en movimiento, el volumen craneal del santo, o el drapeado de las holgadas calzas. ${ }^{38}$

El boceto de Planeta puede sugerir la calidad plástica del pintor y, por el momento, puede ser aprovechado para atribuir mejor la obra de pintura que ejecutó en la capilla Villegas (de calidad desigual en su ejecución), y luego establecer analogías correspondientes con otras obras de la época. ${ }^{39}$

\section{Consideraciones generales}

La obra conocida del pintor Juan Bautista Planeta se identifica efectivamente con la corriente manierista aunque im-

37 El dibujo de Alesio lo reproduce Mesa y Gisbert (1972; p. 67).

38 En el siglo XVI, en Italia, el dibujo llegó a convertirse en un medio artístico aceptado. Incluso el boceto llegó a ser apreciado por los artistas (Moshe Barasch, 2012; pp. 187, 197)

39 En opinión de Chichzola (1983: 166), existe gran similitud entre un personaje con casco de perfil, pintado en los muros del claustro principal del convento de san Francisco, y una figura (en igual actitud) de la capilla Villegas, pero no reprodujo imágenes de las figuras citadas. 
buida con las nuevas ideas y fervor religioso de la Contrarreforma propagadas a finales del siglo XVI, en Lima. Esta propuesta artística se mantenía pues aún en vigor a inicios de la cuarta década del siglo XVII, como puede deducirse igualmente del hecho que el pintor italiano mantuvo su taller activo hasta poco antes de su muerte, con la presencia de al menos dos colaboradores que lo secundaban en el cumplimiento de los encargos encomendados por cierto sector de la clientela limeña.

La actividad del pintor Planeta en Lima (1627-1642) se desarrolló en una época en que los artífices empezaron a crear soluciones artísticas más modernas para la ciudad, como ciertos ejemplos de arquitectura y escultura que prefiguraron el periodo barroco limeño. Según el profesor San Cristóbal, en la arquitectura religiosa se fueron introduciendo "componentes barrocos", que rompían parcialmente con la monotonía renacentista de los edificios (San Cristóbal 1992: 101103), como en las plantas o portadas de algunas iglesias; $;^{40}$ algo similar ocurrió en la escultura con las obras de Pedro Muñoz (1622-1644) que se alejó de fórmulas manieristas y adoptó formas de expresión más humanizadas en la creación de las imágenes (Chuquiray 2017, 2018). En el caso de la pintura debió ocurrir algo parecido, aunque no se pueda afirmar de manera más precisa al respecto debido a la escasez

40 Como el comentado caso de la reconversión de la planta gótico-isabelina del templo de la Merced a una de tres naves abiertas con crucero (16081628); o el innovador diseńo de la portada de la catedral de Lima, imaginada como una portada retablo por Juan Martínez de Arrona, según una memoria fechada en 1632, pero terminada de ejecutar muchos años después (posterior al año 1647) por Pedro de Noguera (San Cristóbal, 1996; pp. 224-247). 
de obras limeñas adjudicadas, con respaldo documental, a la época tratada. Por esta razón, la obra atribuida (mediante documentos) al pintor italiano Juan Bautista Planeta contribuye al panorama de la pintura limeña de la primera mitad del siglo XVII, tiempo de transición entre el Manierismo y la etapa del Barroco.

Por último, es necesario señalar que más allá de las conclusiones inmediatas que pueden extraerse de las noticias inéditas de este texto, debe considerarse darles una lectura más profunda y en perspectiva ya que implican temas de fondo de asunto histórico artístico, como por ejemplo las exigencias de la clientela en la formación del gusto limeńo, el rango social del artífice, la actividad en su casa taller o su papel como intérprete de la sensibilidad de su época. No obstante, es importante indicar que para la historia del arte el objeto de análisis sigue siendo en última instancia la obra de arte, a partir de la cual (identificada en su contexto artístico) parten y se sustentan las consideraciones generales propuestas. Por eso mismo, se hace necesaria la buena conservación de las obras artísticas del Virreinato peruano que por suerte han perdurado hasta ahora, como la conocida capilla del capitán Villegas y la gran labor pictórica conservada en malas condiciones en ella, ahora atribuida a Juan Bautista Planeta, de modo que no se corra el riesgo de perderla.

Recibido: 15 de julio del 2017.

Aprobado: 19 de diciembre del 2018. 


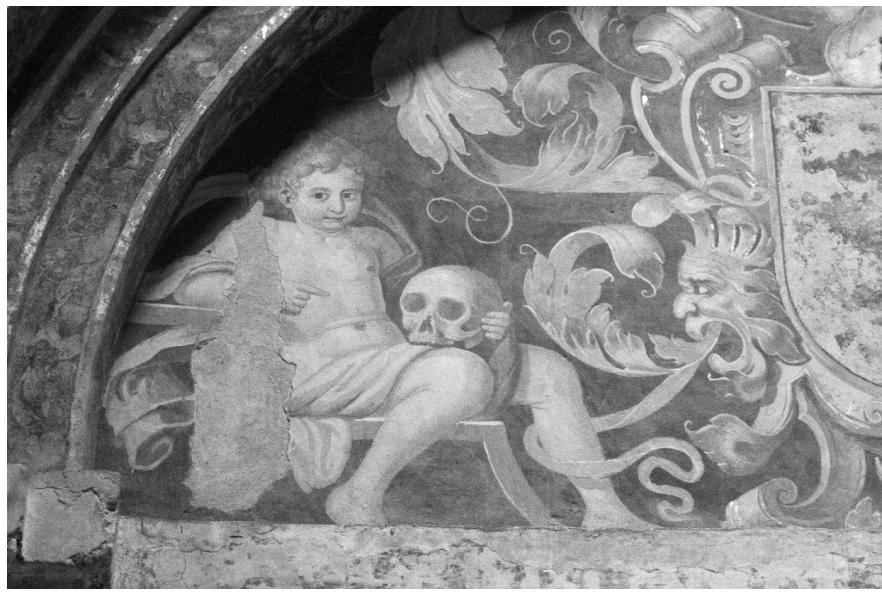

Fig. 1. Juan Bautista Planeta. Capilla de Bernardo de Villegas, en convento de la Merced, ca. 1628-1632

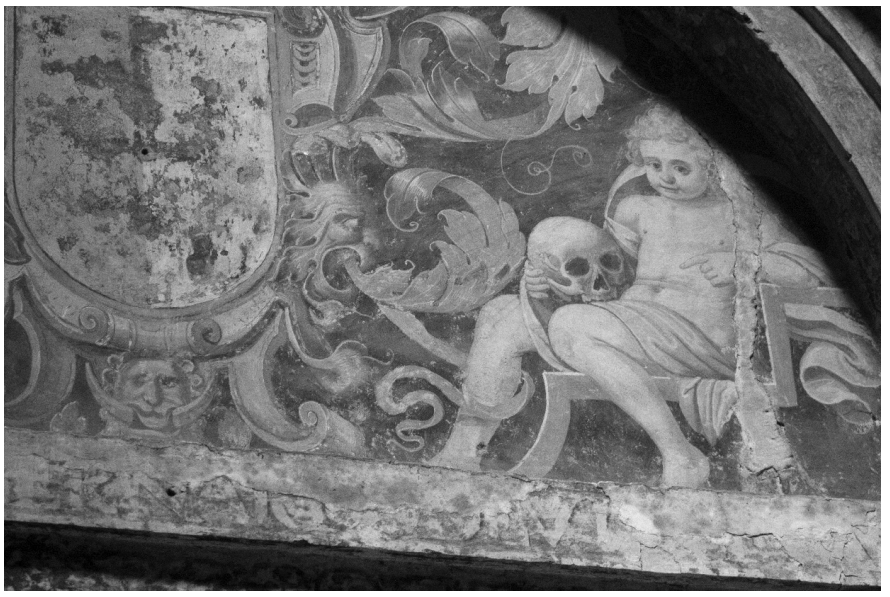

Fig. 2. Juan Bautista Planeta. Capilla de Bernardo de Villegas, en convento de la Merced, ca. 1628-1632 
Trayectoria artística del pintor Juan Bautista Planeta en Lima.

Nuevas noticias y atribución

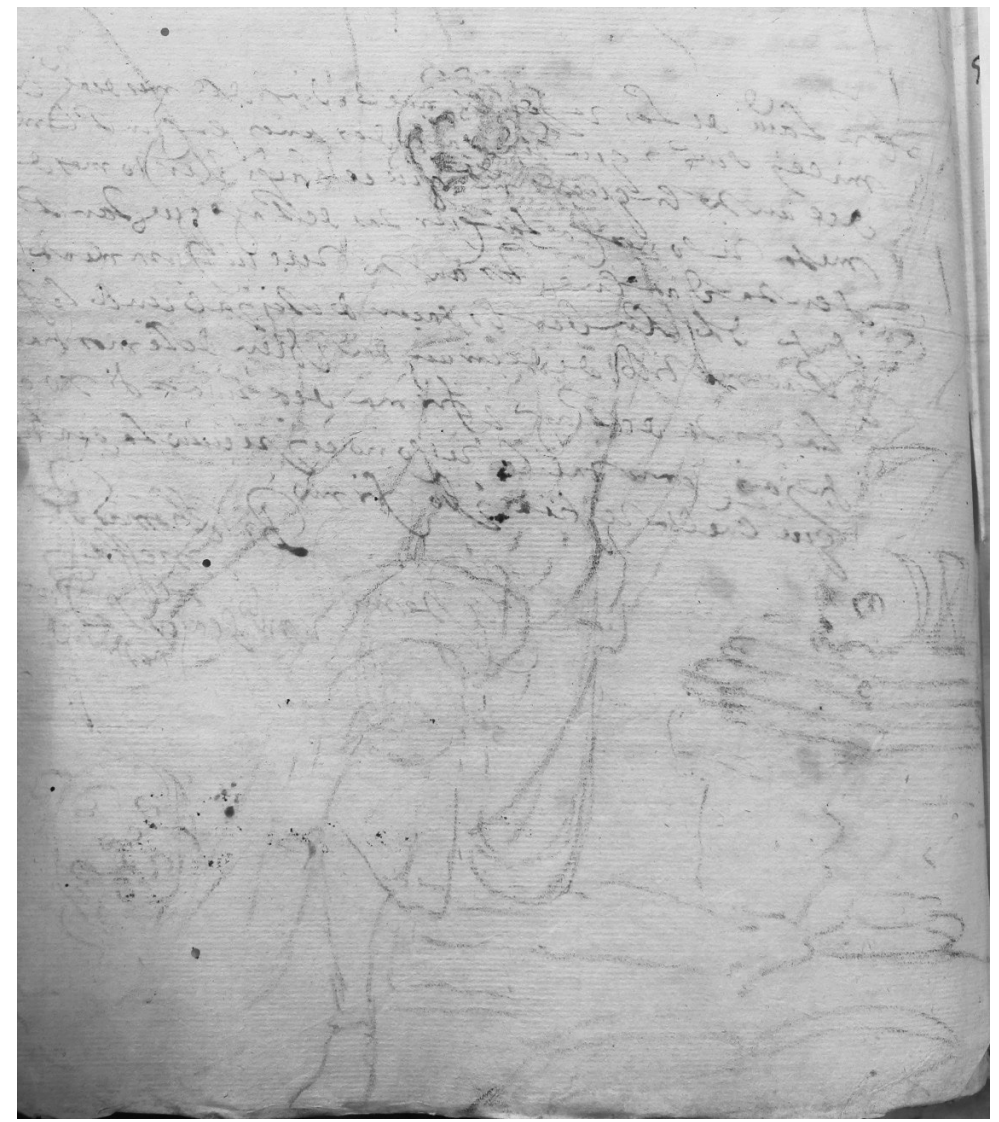

Fig. 3. Juan Bautista Planeta. Boceto de san Jerónimo penitente, ca. 1635-1642. Cortesía: Archivo Arzobispal de Lima. 


\section{Bibliografía}

\section{Fuentes primarias}

Archivo Arzobispal de Lima. Causa de negros, legajo 6, expediente 20, año de 1632.

AAL. Causas civiles, legajo L: 2. Autos que sigue Juan de Guedeja contra juan Bautista Planeta por el salario de procurador. 1640 .

AAL. Pleito de acreedores a los bienes de JBP, legajo 52, expediente 8, año 1642 .

AAL. Cofradías, LV: 7, años 1642-1643.

Archivo General de la Nación, escribano Bartolomé de Cívico, protocolo 320, folios 460v-463v.

AGN, escribano Cristóbal Aguilar Mendieta, protocolo 66, folios 343-346v.

AGN, escribano Diego Sánchez Vadillo, protocolo 1769, folios 2147-2148v.

AGN, escribano Diego Sánchez Vadillo, protocolo1795, folios 513-521v.

AGN, escribano Francisco Gonzáles Balcázar, protocolo 773, folio 96-96v.

AGN, escribano Francisco Hernández, protocolo 825, folios 734$741 \mathrm{v}$.

AGN, escribano Marcos de Santisteban, protocolo 1814, folio $439 \mathrm{v}$.

AGN, escribano Pedro Gonzáles Contreras, protocolo 790, folio 302-306v.

\section{Fuentes secundarias}

Barasch, Moshe

(2012) Teoría del arte. De Platón a Winckelmann. Alianza Forma, Madrid. 
Barriga, Víctor

(1944) El templo de la Merced de Lima. Arequipa.

Chichizola Debernardi, José

(1983) El manierismo en Lima. Lima. Pontificia Universidad Católica del Perú.

Chuquiray Garibay, J.

(2017) "El escultor Pedro Muñoz y la impronta de Gregorio Fernández en su obra limeña”, en III Simposio de Jóvenes investigadores del Barroco Iberoamericano, Sevilla.

(2018) La escultura en Lima en la primera mitad del siglo XVII. La Sagrada Familia de Pedro Muñoz. Comisión de Liturgia de la Conferencia Episcopal Peruana, Lima.

Estabridis Cárdenas, Ricardo

(1982) "Enigmas de San Francisco", en El Comercio, 19 de diciembre de 1982.

"Influencia italiana en la pintura virreinal", en Pintura en el Virreinato del Perú. Banco de Crédito del Perú, Lima.

Hart-Terré, Emilio y Alberto Márquez Abanto

1963 Las bellas artes en el Virreinato del Perú. Pinturas y pintores en Lima virreinal”, en Revista del Archivo Nacional del Perú, Enero-Diciembre, tomo XXVII, entregas 1 y 2 ,

Mesa, José de y Teresa Gisbert

(1972) El pintor Mateo Pérez de Alesio. La Paz, Universidad Mayor de San Andrés, Instituto de Estudios Bolivianos.

Lohmann Villena, Guillermo

"Noticias inéditas para ilustrar la historia de las Bellas Artes en Lima durante los siglos XVI y XVII". Revista histórica. Lima t. XIII. 
Ramos Sosa, Rafael

(2000) "Martín Alonso de Mesa, escultor y ensamblador", en: Anales del Museo de América, no 8.

Rivarola, José Luis

(2009) Documentos lingüisticos del Perú: siglos XVI y XVII: edición y comentario. Consejo superior de investigaciones científicas, Madrid.

San Cristóbal, Antonio

Estudios de la arquitectura virreinal. Patronato de Lima. Epígrafe editores S.A., Lima, Perú.

San Cristóbal, Antonio

(2001) La iglesia y el convento de San Agustín de Lima. Oficina de Impresiones: Colegio San Agustín, Lima, Perú.

San Cristóbal, Antonio

(2005) Arquitectura virreinal de Lima en la primera mitad del siglo XVII. II tomo, Lima, Perú.

San Cristóbal, Antonio

(2009) Arquitectura virreinal de la iglesia y convento de la Merced de Lima. UNI, Lima, Perú.

Schenone, Héctor

"Una pintura en Lima, atribuida a Pérez de Alesio", en Anales del instituto de arte americano e investigaciones estéticas. Universidad de Buenos Aires, 16.

Stastny, Francisco

(2013) "El manierismo en la pintura colonial latinoamericana” en Estudios de arte colonial, Volumen I, MALI.

"Pérez de Alesio y la pintura del siglo XVI", en Estudios de arte colonial, Volumen I, MALI.

Vargas Ugarte, Rubén

1947 Ensayo de un diccionario de artifices de la América meridional. Talleres gráficos A. BAIOCCO Y Cía, S.R.L. 
Vargas Ugarte, Rubén

1968 Ensayo de un diccionario de artifices de la América meridional. Burgos, España.

Wuffarden, Eduardo

1976 "La capilla del Capitán Villegas" en La Prensa, Suplemento "La Imagen" 26 de diciembre de 1976, Lima, p. 19. 